\title{
Effect of Laser Heat Treatment on the Microstructure and Properties of Alloy $800 \mathrm{H}$
}

\author{
Wei Zhang *(D), Tao Jiang *, Jing Li and Liqiang Liu \\ College of Mechanical and Electric Engineering, Changchun University of Science and Technology, \\ Changchun 130022, China; lijingdufeng@126.com (J.L.); 13843155571@163.com (L.L.) \\ * Correspondence: zhangwei1@cust.edu.cn (W.Z.); jiangtao@cust.edu.cn (T.J.)
}

Received: 28 February 2019; Accepted: 22 March 2019; Published: 25 March 2019

\begin{abstract}
The effects of laser heat treatment on the microstructure and properties of alloy $800 \mathrm{H}$ were investigated. The fracture morphology, elemental changes, and phase composition of the specimens were characterized by scanning electron microscopy (SEM), energy dispersive spectroscopy (EDS), and X-ray diffractometry (XRD). The results show that the long-lasting life of the specimen after laser heat treatment increased by $28.6 \%$, and the elongation after fracture increased by $20.7 \%$. The macroscopic morphology of the fracture specimen exhibited obvious ductile fracture morphology, and the changes in the elemental content and grain size significantly affected the ductility and toughness of the alloy. This study has certain guiding significance for the optimization of the heat treatment process of this type of alloy.
\end{abstract}

Keywords: alloy $800 \mathrm{H}$; laser heat treatment; longevity; grain size

\section{Introduction}

Alloy $800 \mathrm{H}$ is a typical austenitic heat-resistant iron-nickel-based alloy with a high temperature creep resistance and good mechanical properties. It is widely used in petrochemical pipelines, heat transfer tubes of steam generators, and industrial furnace pipes with their accessories [1]. Therefore, we mainly studied the hot deformation behavior, high temperature creep behavior, and stress corrosion resistance of alloy $800 \mathrm{H}$ during its application process. There have been few studies on the influence of heat treatment on the microstructure and properties of this alloy. Most of them have been based on the solid solution treatment, which controls the grain size of the alloy and improves its mechanical properties [2-5]. For example, Gong et al. [6] considered that the solution temperature has a significant effect on the mechanical properties of the alloy at room temperature and its grain size, the effect of holding time is not obvious, and the increase in temperature mainly affects its plasticity. Huang et al. [7] suggested that the solution treatment temperature has a great influence on the grain size of the alloy. During the gradual increase in temperature, the intracrystalline chromium carbides are basically dissolved, so that the grain size and hardness are in accordance with the Hall-Petch relationship.

With the appearance of high-power lasers, heat treatment methods are no longer limited to solution treatment. Laser heat treatment is a new type of high energy density strengthening method, which is mainly used for the heat treatment of materials such as steel and cast iron to improve their microstructures and mechanical properties [8]. For example, Jiang et al. demonstrated that laser instantaneous annealing softening can effectively reduce a material strength's after work hardening as well as improve the plasticity of the material and restore its large deformation ability [9]. Based on this, the influence of laser heat treatment on the microstructure and properties of alloy $800 \mathrm{H}$ was studied. 


\section{Materials and Methods}

Experiment material: The test material was a forged alloy $800 \mathrm{H}$ produced by Shanghai Jinshun Stainless Steel Material CO., Ltd. (Shanghai, China) and a $\Phi 16 \mathrm{~mm}$ steel bar obtained by multiple hot forging treatment of the slab, and the main chemical composition of $800 \mathrm{H}$ is shown in Table 1.

Table 1. Chemical composition of the alloy $800 \mathrm{H}$ (mass fraction, \%).

\begin{tabular}{ccccccccccccc}
\hline $\mathbf{C}$ & $\mathbf{M n}$ & $\mathbf{S i}$ & $\mathbf{N i}$ & $\mathbf{C r}$ & $\mathbf{M o}$ & $\mathbf{S b}$ & $\mathbf{C u}$ & $\mathbf{A l}$ & $\mathbf{T i}$ & $\mathbf{C o}$ & $\mathbf{A s}$ & $\mathbf{F e}$ \\
\hline 0.06 & 1.100 & 0.500 & 34.790 & 22.170 & 0.047 & 0.0014 & 0.024 & 0.150 & 0.380 & 0.015 & 0.015 & margin \\
\hline
\end{tabular}

Experiment method: There were two groups of round bar samples. One group was subjected to laser heat treatment using a $\mathrm{CO}_{2}$ laser at $2500 \mathrm{~W}$ with a moving speed of $0.3 \mathrm{~m} / \mathrm{min}$, an irradiation wavelength of $10.6 \mu \mathrm{m}$, a focal length of $353 \mathrm{~mm}$, and a spot focus diameter of $0.3 \mathrm{~mm}$. During the heat treatment, the sample was fixed, the laser was moved and heated, and air cooling with the cooling rate of $5^{\circ} / \mathrm{s}$ was performed. The box type resistance furnace (Shenyang Xing Shen Warming Power Equipment Manufacturing Co., Ltd., Shenyang, China) was heated to $910{ }^{\circ} \mathrm{C}$, kept for $2 \mathrm{~h}$, and then cooled in a furnace at the rate of $0.06^{\circ} / \mathrm{s}$. The other set of samples was not heat-treated.

The round bar sample after heat treatment was processed into a test sample according to the size. The specific dimensions are shown in Figure 1. A test sample of alloy $800 \mathrm{H}$ was made using a Computerized Numerical Control lathe and a grinding machine.

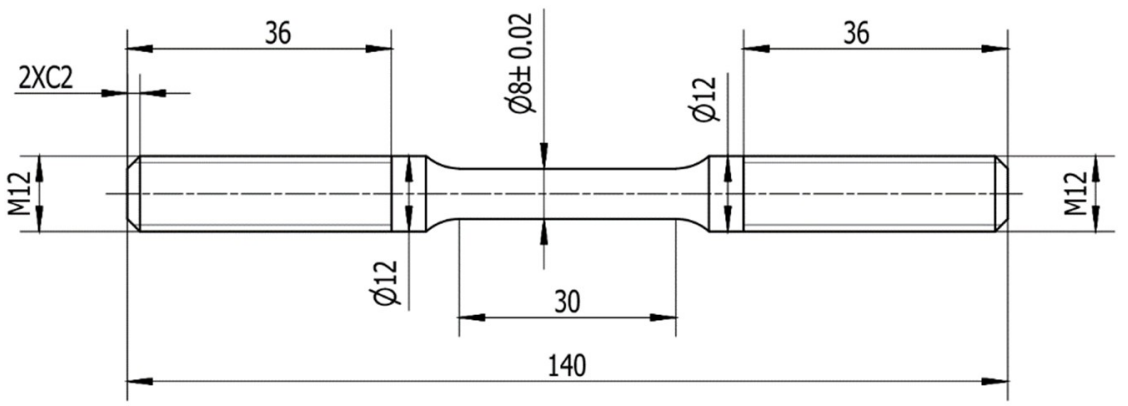

Figure 1. Sample size.

Two sets of non-heat-treated samples and laser heat-treated samples were subjected to a long-term performance test using a variable temperature and a long-lasting performance test device (Sinotest Equipment Co., Ltd., Changchun, China). Test conditions: The temperature was $584-800{ }^{\circ} \mathrm{C}$, the temperature loading speed was $34^{\circ} \mathrm{C} / \mathrm{min}$, and the force was $2-5 \mathrm{kN}$.

Sample characterization: The microstructure of the fracture surface was observed by scanning electron microscopy (SEM, EVO18, Beijing, China). The fracture surface and the changes in alloying elements in the middle were analyzed by energy dispersive spectroscopy (EDS). The surface of the alloy was analyzed by an X-ray diffractometer (XRD, Brussells, Belgium).

\section{Results and Discussion}

\subsection{Effect of Laser Heat Treatment on Microstructure and Durability of Alloy}

Figure 2 is a deformation-time curve of the samples-one with laser heat treatment and the other without treatment. It can be seen that creeping occurred in both samples in the temperature range of $584-800{ }^{\circ} \mathrm{C}$, indicating that the alloy underwent creep rupture during the heating process. The rupture times of the laser heat treatment and untreated samples were 45 and $35 \mathrm{~h}$, respectively. The longevity increased by $28.6 \%$, the maximum deformations were 6.205 and $3.195 \mathrm{~mm}$, respectively, and the elongation increased by $20.7 \%$. 


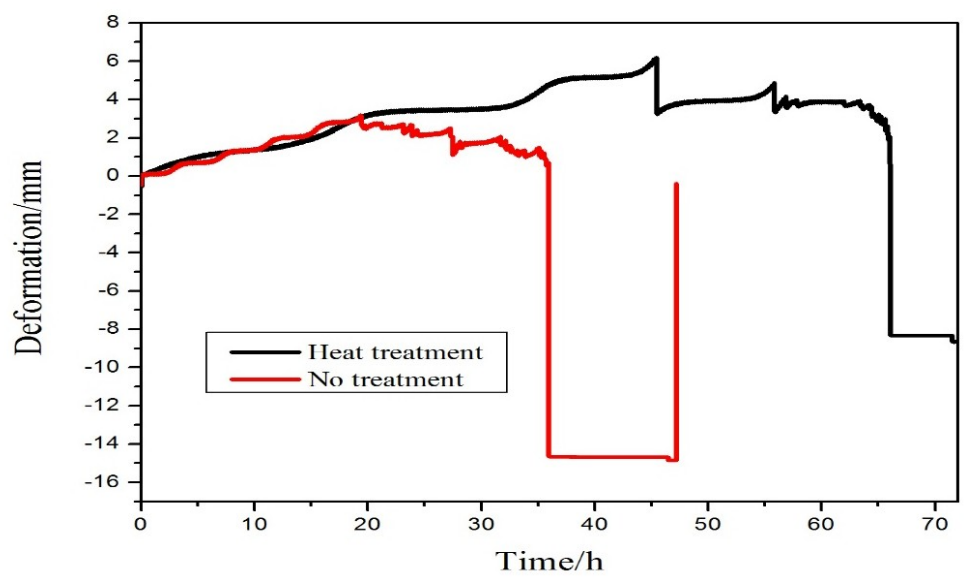

Figure 2. The deformation-time curve of the samples.

To further analyze the creep rupture mechanism, the microstructure and fracture morphology were analyzed by metallographic microscope (Leica DM2700, Beijing Ruike Zhongyi Technology Co., Ltd., Beijing, China) and SEM. Figures 3 and 4 are the metallographic structure and fracture profile of samples without treatment and with laser heat treatment, respectively. It can be seen in Figure 3 that the austenite structure of the alloy with laser heat treatment exhibited recrystallization under the action of creep temperature, and the carbide between grains gradually dissolved, the crystal grains grew rapidly, and there was no obvious coarse grains, thereby more uniform alloy structure was obtained. Figure 4 shows an obvious necking phenomenon for the two groups, which proved the material had good elongation, and the fracture of the samples was of the ductile fracture type. There was obvious macroscopic plastic deformation near the fracture, the fracture appearance was cup-shaped, the fracture surface was fibrous, and the color was gray. However, in Figure 4a, it can be seen that, when the alloy sample was plastically deformed under external load, the alloy had a slip along a certain crystallographic plane and direction. Since the alloy material was polycrystalline, it deformed. During the process of intensification, a continuous wave pattern formed. In Figure $4 \mathrm{~b}$, the alloy sample is shown to have a relatively obvious dimple fracture, and the shape of the dimple on the fracture surface was the same, thus the fracture was of the equiaxed dimple type. Between dimples of different sizes, there was a situation in which large dimples were densely surrounded by small dimples. In comparison, it can be determined that the fracture of the sample after laser heat treatment had fibrous morphology with strong plastic deformation marks around the edge of the fracture. The necking phenomenon was obvious, and the dimple size was large and met the requirements of metal ductile fracture morphology. It was proven that laser heat treatment could improve the material's plasticity. In the high temperature test state, the final creep rupture of the sample was promoted, and a relatively uniform microstructure was obtained to improve its longevity.

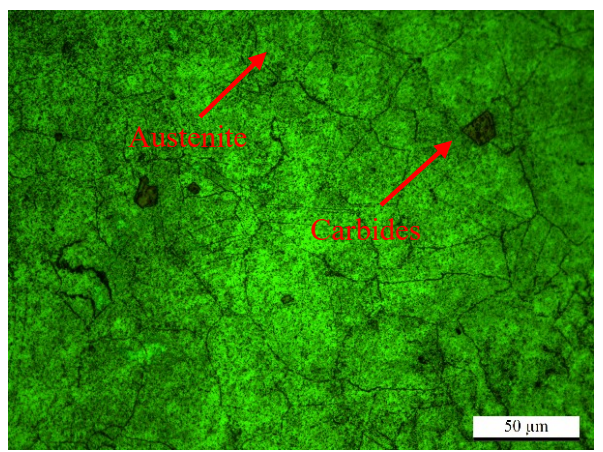

(a) A sample without treatment

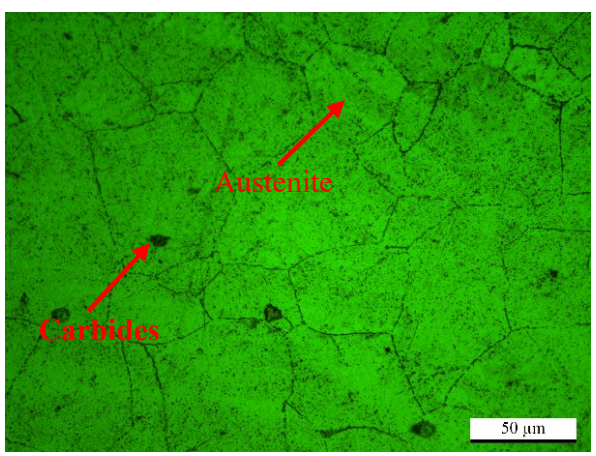

(b) One with laser heat treatment

Figure 3. Microstructure diagram of alloy sample. 

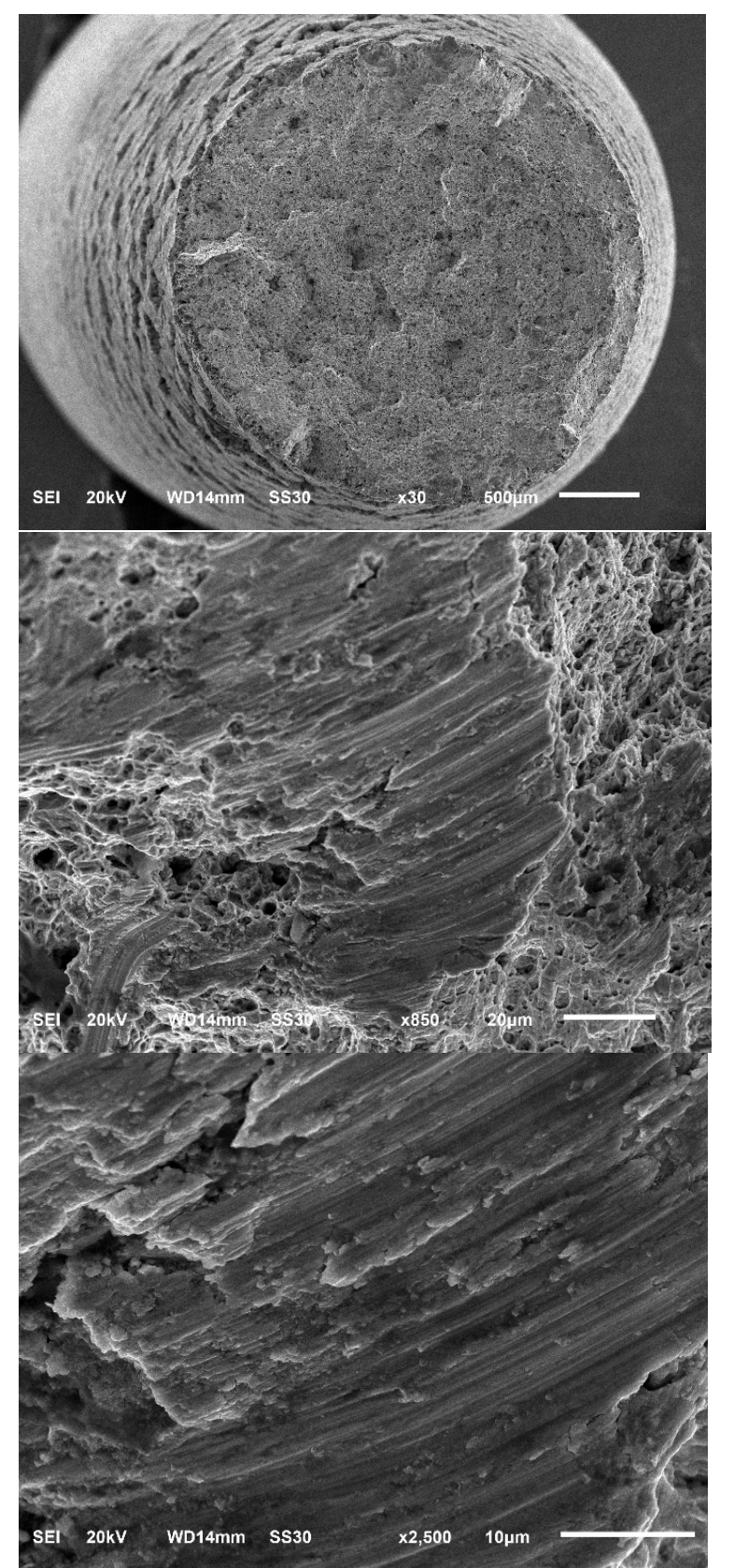

(a) A sample without treatment
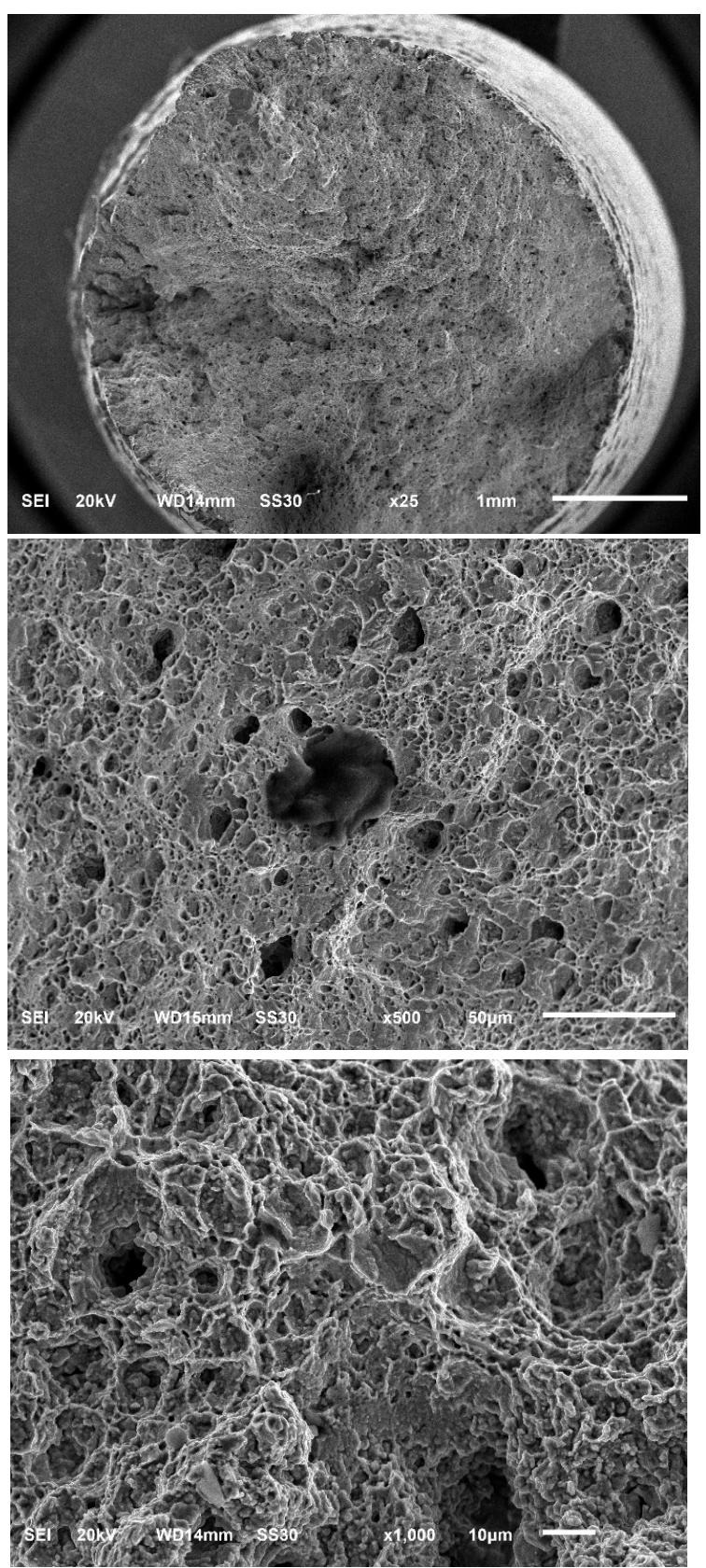

(b) One with laser heat treatment.

Figure 4. Fracture diagram of alloy sample.

\subsection{Effect of Laser Heat Treatment on the Dissolution of the Second Phase}

Wang [10] pointed out that there are many TiN inclusions inside alloy $800 \mathrm{H}$, making it easy to induce crack formation in the alloy and reduce its longevity. $\mathrm{Xu}$ [11] pointed out that laser heat treatment was beneficial for the dissolution of Ti and $\mathrm{N}$ elements in the alloy phase, which reduced their content. This reduced the amount of TiN as well as the probability of germination and cracking, effectively improving its longevity.

Table 2 and Figure 5 show the results of the energy spectrum analysis of alloy $800 \mathrm{H}$ after no treatment and laser heat treatment. The results show that there were still many undissolved Ti inclusions inside the untreated sample, indicating that the internal dissolution of the original alloy was insufficient. However, the internal alloying elements of the sample diffused well after laser heat treatment: the inclusions of Ti element fully dissolved in the matrix, the content of specific gravity 
significantly reduced, and the amount of TiN reduced, thereby reducing the probability of germination cracking and improving the longevity.

Table 2. Element composition results of sample by energy spectrum analysis.

\begin{tabular}{ccccccccc}
\hline Element Distribution & $\mathbf{F e}$ & $\mathbf{N i}$ & $\mathbf{C r}$ & $\mathbf{M n}$ & $\mathrm{Si}$ & $\mathrm{Al}$ & $\mathbf{C u}$ & $\mathbf{T i}$ \\
\hline No treatment, $\mathbf{W t} \%$ & 45.1 & 29.3 & 21.6 & 1.0 & 1.6 & 0.9 & 0 & 0.4 \\
laser heat treatment, $\mathbf{W t} \%$ & 43.9 & 24 & 27.3 & 2.1 & 1.5 & 0.9 & 0.2 & 0.1 \\
\hline
\end{tabular}

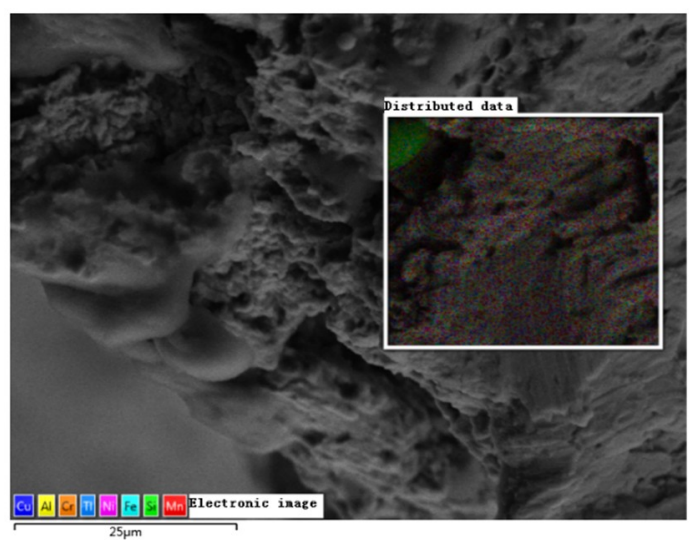

(a) No treatment

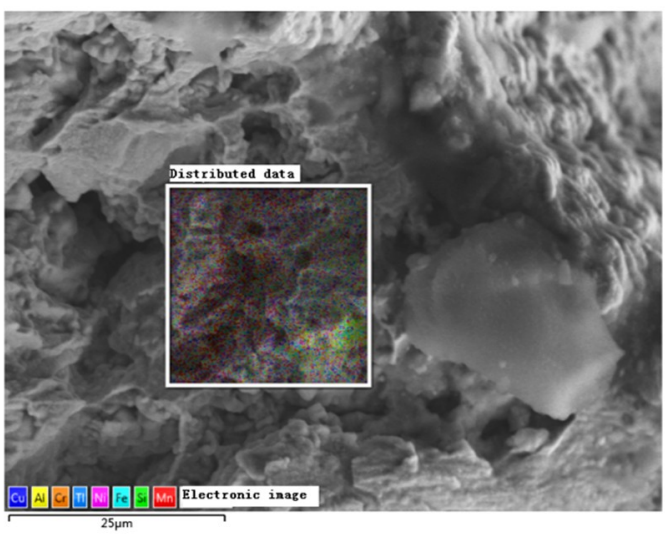

(b) Laser heat treatment

Figure 5. Energy spectrum layered diagram of alloy $800 \mathrm{H}$.

The specific gravity of the $\mathrm{Cu}$ element in the laser heat-treated sample increased to $0.2 \%$, which improved the strength and toughness of the alloy effectively. The content of $\mathrm{Cu}$ did not exceed $0.5 \%$, and it did not cause hot brittleness, thus increasing the long-lasting life of the alloy.

\subsection{XRD Quantitative Analysis}

The plastic properties of an alloy are closely related to its structure. To determine the correlation between alloying elements and their properties, the relative contents of the elements were quantitatively analyzed by XRD. The main three diffraction peaks were selected by Jade software, which were peak shapes of 111, 200, and 220. After the selected peaks had been fitted with peak shapes, the area and grain size of the strongest diffraction peak were calculated. The results are shown in Figure 6 and Table 3.

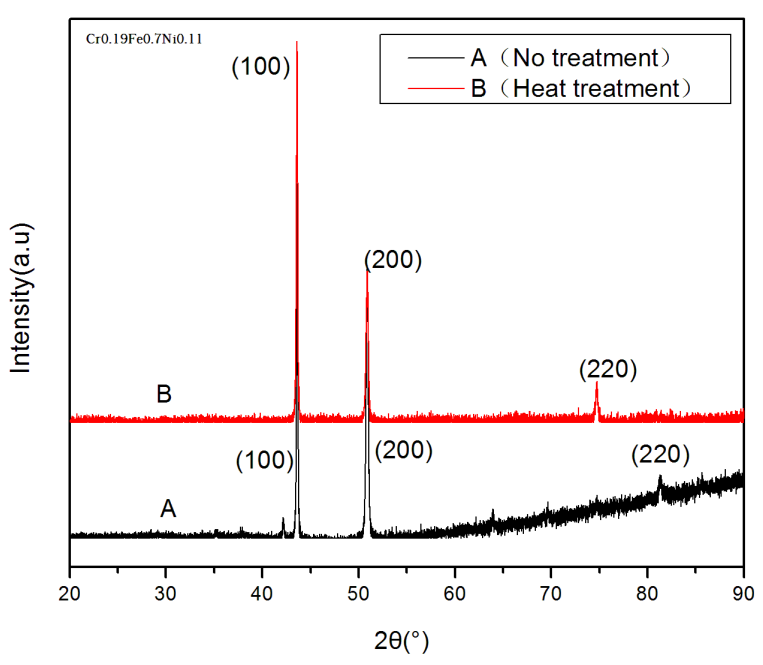

Figure 6. The surface composition of the sample. 
Table 3. Sizes of the strongest diffraction peak of alloy $800 \mathrm{H}$ in two states (nm).

\begin{tabular}{cccc}
\hline Specimen & $\mathbf{1 0 0}$ & $\mathbf{2 0 0}$ & $\mathbf{2 2 0}$ \\
\hline No treatment & 14 & 6 & 26 \\
Heat treatment & 9 & 7 & 34 \\
\hline
\end{tabular}

The XRD patterns of the samples after no treatment and laser heat treatment are shown in Figure 6. It was observed that the processing surface components of the two samples were mainly composed of $\mathrm{Fe}, \mathrm{Ni}$ and $\mathrm{Cr}$, and the main components did not change. However, the contents of $\mathrm{Ni}$ and $\mathrm{Cr}$ changed, and the results of specific content could be analyzed by referring to the results in Table 3 .

Table 3 shows the area and the grain size of the strongest diffraction peak of alloy $800 \mathrm{H}$ after no treatment and laser heat treatment. It shows that the main content of the elements reduced, which indicates that the internal crystal dissolution process of the alloy strengthened after the laser heat treatment, and the grain sizes of the $\mathrm{Ni}$ and $\mathrm{Cr}$ elements increased-that is, the smaller was the connection point of the crystal structure, the greater was the degree of crystallization, and the better were the plasticity and toughness of the alloy, the higher was the durability.

\section{Conclusions}

It was found that laser heat treatment had obvious influence on the microstructure and properties of alloy $800 \mathrm{H}$. The specific impact results are as follows:

(1) The long-lasting life of the laser heat-treated samples increased by $28.6 \%$, and the elongation after the break increased by $20.7 \%$. Therefore, laser heat treatment affected the durable life and elongation of the alloy to varying degrees. After laser heat treatment, the tensile fracture morphology of the alloy specimen showed ductile fracture and a uniform microstructure was obtained.

(2) After laser heat treatment, the specific gravity of the Ti content in alloy $800 \mathrm{H}$ obviously reduced, making the inclusion of the Ti element more soluble. It reduced the number of TiN, reduced the probability of crack initiation and improved the longevity of the alloy.

(3) After laser heat treatment with alloy $800 \mathrm{H}$, the grain sizes of $\mathrm{Ni}$ and $\mathrm{Cr}$ elements increased to different extents. This shows that the effect of laser heat treatment on grain size was more significant, and the alloy could obtain a more uniform microstructure after heat treatment.

Author Contributions: Conceptualization, W.Z. and L.L.; methodology, W.Z.; software, W.Z.; validation, W.Z., T.J. and L.L.; formal analysis, T.J.; investigation, T.J.; resources, J.L.; data curation, W.Z; writing—original draft preparation, W.Z.; writing—review and editing, W.Z.; visualization, W.Z.; supervision, T.J.; project administration, J.L.; funding acquisition, J.L.

Funding: This study was funded by China National Youth Nature Fund, (grant number 51505039).

Conflicts of Interest: The authors declare no conflict of interest.

\section{References}

1. Berka, J.; Vilémová, M.; Sajdl, P. Testing of degradation of alloy $800 \mathrm{H}$ in impure helium at $760{ }^{\circ} \mathrm{C}$. J. Nucl. Mater. 2015, 464, 221-229. [CrossRef]

2. Cao, Y.; Di, H.; Zhang, J.; Ma, T.; Zhang, J. Research on hot deformation behavior and hot workability of alloy 800H. Acta Metall. Sin. 2013, 49, 811-821. (In Chinese) [CrossRef]

3. Peng, J.; Tang, X.; He, J.; Xu, D. Effect of heat treatment on microstructure and tensile properties of A356 alloys. Trans. Nonferr. Met. Soc. China 2011, 21, 1950-1956. [CrossRef]

4. Yang, J.; Li, J.; Wang, M.; Wang, Y.; Jin, T.; Sun, X. Effects of heat treatment process on the microstructure and properties of a new cast nickel-based superalloy. Acta Metall. Sin. 2012, 48, 654-660. (In Chinese) [CrossRef]

5. Li, Y.; Zhang, L.; Zhu, Z.; Li, H. Influence of heat treatment on microstructure and mechanical properties of a high-strength Zr-Ti alloy. Acta Metall. Sin. 2014, 20, 19-24. (In Chinese)

6. Gong, B.; Li, Y.; Cheng, M. Influence of solution treatment on microstructure and mechanical properties of forged $800 \mathrm{H}$ alloy. Heat Treat. Met. 2018, 43, 148-152. (In Chinese) 
7. Huang, Y.; Dai, Q.; Li, D.; Cheng, X.; Tao, Y.; Liu, Y. Effect of solution treatment on microstructure and hardness of $800 \mathrm{H}$ alloy. Heat Treat. Met. 2012, 37, 73-77. (In Chinese)

8. Jinoop, A.N.; Paul, C.P.; Bindra, K.S. Parametric study on laser additive manufacturing and subsequent post processing of inconel 718 thin walled structures. In Proceedings of the ASME 2017 Gas Turbine India Conference, Bangalore, India, 7-8 December 2017.

9. Jiang, K.; Wang, L. Study on Laser Annealing Softening Process of 316L Stainless Steel. Surf. Technol. 2019, 48, 10-16.

10. Wang, F.; Wang, E.; Jia, P.; Wang, T.; Deng, A. Effect of Electromagnetic Continuous Casting on TiN Distribution and Internal Crack in incoloy 800H Alloy Billet. Acta Metall. Sin. 2017, 1, 97-106. (In Chinese)

11. Xu, H.; Zhou, J.; Yuan, G.; Dai, F. Mechanism of laser heat treatment to improve material life. Electromach. Mould 2000, 5, 28-30.

(C) 2019 by the authors. Licensee MDPI, Basel, Switzerland. This article is an open access article distributed under the terms and conditions of the Creative Commons Attribution (CC BY) license (http://creativecommons.org/licenses/by/4.0/). 